РЫБАКОВА Марина Владимировна - доктор социологических наук, главный научный сотрудник Института социологии ФНИСЦ РАН (117218, Россия, г. Москва, ул. Кржижановского, 24/35, корп. 5); профессор факультета государственного управления Московского государственного университета им. М.В. Ломоносова (119991, Россия, г. Москва, Ломоносовский пр-кт, 27, корп. 4; Rybakovamv2005@yandex.ru)

ЗЕРНОВА Людмила Павловна - кандидат философских наук, доцент Московского физико-технического института (национальный исследовательский университет) (141701, Россия, Московская обл., г. Долгопрудный, Институтский пер., 9; zlp55@yandex.ru)

\title{
«ЦИФРА» И РОССИЙСКОЕ ОБРАЗОВАНИЕ: УПРАВЛЕНЧЕСКИЕ АСПЕКТЫ
}

\begin{abstract}
Аннотация. В статье рассматриваются проблемы, связанные с цифровизацией российского общества, а также основные факторы и вызовы, связанные с образовательной подготовкой современных кадров для повышения конкурентоспособности экономики России в глобальном мире. Авторы отмечают, что ключевой фактор роста производительности человеческого капитала - развитие креативности и творческого потенциала современных выпускников школ и вузов.
\end{abstract}

Ключевые слова: цифровизация, управление, образование, креативность, гуманизм

$\mathrm{O}$ тличительной чертой второй половины XX - начала XXI в. является трансформация различных сторон жизни глобального мира и переход на новый технологический уклад, создание новых траекторий движения цивилизации.

В России точкой отсчета развития цифровой экономики можно считать послание президента РФ Федеральному собранию от 01.12.2016: «Предлагаю запустить масштабную системную программу развития экономики нового технологического поколения, так называемой цифровой экономики. В ее реализации будем опираться именно на российские компании, научные, исследовательские и инжиниринговые центры страны» 1 .

В то же время понятие «цифровизация» (digitization, оцифровка) приобретая все большее распространение в России, остается достаточно расплывчатым в сознании массовых слоев населения и употребляется наряду с близкими по содержанию понятиями «информатизация» и «компьютеризация». Вместе с тем каждое из этих близких по содержанию понятий подчеркивает определенный аспект процесса становления современной техногенной цивилизации, названной «информационным обществом», или «обществом знаний» [Леньков, Боровлева 2018: 149].

Мы можем наблюдать реальные социальные последствия компьютеризации, такие как:

- изменение характера производственной деятельности во многих отраслях промышленности;

- изменение коммуникационных стратегий, появление определенных новых социальных групп, жизнедеятельность которых непосредственно связана с компьютерными сетями;

- появление новых видов интеллектуальной деятельности, а следовательно интеллектуальной собственности;

- становление «киберкультуры», переоценка ценностей.

Меняются основы жизнедеятельности общества, ценностные ориентиры и

1 Послание Президента РФ Федеральному Собранию от 01.12.2016. Доступ: http://www. consultant.ru/document/cons_doc_LAW_207978/(проверено 25.07.2020). 
психологические черты людей, формируя новые социальные группы, компьютеризация и цифровизация предстают как глобальные социальные процессы [Швецов 2012]. Интернет действительно позволяет искать, получать и распространять информацию и идеи независимо от государственных границ.

На молодежь как наиболее активную и мобильную социальную группу ложится наибольшая нагрузка по цифровизации общества и овладению новыми навыками - не только профессиональными, но и личностными.

Не случайно современную молодежь называют «цифровыми аборигенами», для которых характерно клиповое сознание, поверхностное восприятие и мышление, низкий уровень рефлексии и эмоционального интеллекта. Скорость использования интернет-ресурсов в молодежной среде опережает формирование ценностей, норм, стратегий поведения и создает новые условия для последующих рисков. Человек, имеющий современную модель телефона и доступ к Интернету, быстрее потребляет информацию, но не анализирует ее, следовательно, не приобретает новые знания. Современная изощренная реклама нарушает защитные механизмы психики человека, мозг которого не успевает приспособиться к скорости обработки информации.

Авторы ставят своей целью рассмотреть основные риски и вызовы современного цифрового общества, а также определить траекторию управления системой образования как важнейшим социальным институтом, т.к. именно сфера образования обеспечивает экономику конкурентоспособными, креативными, талантливыми кадрами.

Согласно результатам научного проекта Финансового университета при Правительстве РФ «Влияние цифровизации на профессиональную культуру российской молодежи» 2018 г., большинство молодых людей в России являются жителями цифрового пространства, о чем свидетельствует ранний старт в использовании интернет-коммуникации: $25 \%$ начинают в 7-10-летнем возрасте; 45,5\% - в 10-13-летнем; еще 1/4 - в возрасте старше 13 лет. При этом самая существенная доля молодых россиян проводит 1/3 дня в социальном пространстве: $40 \%-4-8$ ч; 34\% - 1-4 ч; $15 \%$ - 8-12 ч; $6 \%$ - более 12 ч [Бродовская 2019: 65].

Если говорить непосредственно об активных пользователях Интернета, то $48 \%$ из них признаются, что слишком много времени проводят, блуждая по просторам «всемирной паутины», а $34 \%$ - что засиживаются в социальных сетях. $44 \%$ россиян в возрасте 18-24 лет признаются, что Интернет и социальные сети отнимают у них много времени. Эти же респонденты склонны чаще остальных указывать на излишнюю трату времени на использование мобильного телефона или смартфона (39\%). К сожалению, пожилые россияне чаще остальных групп населения признаются, что слишком много времени тратят на просмотр телевидения (28\% против $14 \%$ среди молодежи) ${ }^{1}$.

По данным социологических исследований, не только взрослые, но и дети являются активными пользователями Интернета и с 4 лет принимают активное и регулярное участие в просмотре роликов, состоят в детских группах на видеохостинге YouTube ${ }^{2}$.

Аналитический центр Social Blade, использующий мировую статистику, отмечает, что на платформе YоиТиье представлены 130 тыс. детских каналов для аудитории до 7 лет. Число подписчиков канала возросло до 6 млрд чел., а число

1 Опрос ВЦИОМ. Интернет-зависимость: сколько россиян подвержены «болезни XXI века»? Доступ: https://wciom.ru/index.php?id=236\&uid=1104 (проверено 25.07.2020).

2 Made for Kids \& COPPA - Initial Look at the YouTube Data. URL: https://socialblade.com/ blog/made-for-kids-initial-look-at-the-data/ (accessed 25.07.2020). 
просмотров достигло до 2,5 трлн. При этом отмечается, что платформа YouTube одна из многих размещает контент только тогда, когда осуществляются реальные просмотры ${ }^{1}$.

К сожалению, информация, поступающая с видеоклипов, не всегда несет позитивный смысл, а чаще всего - манипулятивный, связанный с социальными рисками и угрозами.

Тотальная цифровизация и внедрение информационно-коммуникационных технологий является естественным и закономерным процессом и, следовательно, неизбежным. Базовой причиной расширения цифрового сегмента, прежде всего экономики, является рост трансакционного сектора (государственное управление, информационное обслуживание, консалтинг, финансы, сфера услуг и др.) [Савина 2018: 580].

Как правило, все новое и передовое наряду с позитивными тенденциями и проявлениями сталкивается с определенными негативными последствиями, которые необходимо отслеживать и своевременно ими управлять.

Для цифрового общества характерны фундаментальные риски, такие как специфическая система ценностей, созданная на основе корректировки представлений прошлых поколений и создания собственных, связанных с доминированием знаний интернет-пространства; изменение психофизиологии человека: когнитивной, ментальной, коммуникативной и аксиологической сфер.

Динамичный процесс трансформации общества стремительно обгоняет биологическое время и с трудом поддается осмыслению привычными концепциями, не позволяет адекватно строить долгосрочные прогнозы.

К фундаментальным рискам можно отнести снижение ценности самого человека, вытеснение людей из сферы производства и внедрение искусственного интеллекта, трансформацию рынка труда и управления в целом, производство «лишних людей», снижение ценности образования и инфляцию дипломов, формирование новой цифровой культуры, снижение биологического разнообразия и разрушение глобального азотного цикла, проблемы с потреблением пресной воды и многое другое [Шаповалова 2015: 149].

Человек в цифровом обществе теряет неприкосновенность личного пространства, его ежечасная деятельность (использование электронных систем оплаты, общение в чатах и социальных сетях, посещение страниц сайтов, обращение к порталам услуг, запросы в поисковиках, отправление электронной почты, покупки в интернет-магазинах и т.д.) позволяет по цифровому следу составить исчерпывающий портрет личности ${ }^{2}$.

В связи с таким положением возникают вполне реальные угрозы кибератак, кибербуллинга, зомбирования посредством воздействия на подсознание. Следует учитывать, что особенностью цифрового общества является отсутствие права у человека на созидательное, безопасное одиночество, провоцирующее процессы самопознания, осознания своего места в окружающем мире, цели своего существования, способствующее духовному развитию. Кроме того, в человеческом сознании иногда стирается разделительная черта между реальным миром и виртуальным: иллюзорный мир вытесняет действительность в общении, в самореализации, в аккумуляции собственного практического действия. Виртуальное пространство не спасает от одиночества, вызывает повы-

1 Политика компании YouTube. Доступ: https://www.youtube.com/t/terms/ (проверено 25.07.2020).

${ }^{2}$ Хель И. Нас ждут дизайнерские младенцы и новые технологии создания детей. $-\mathrm{Hi}$-news. Доступ: https://yandex.ru/turbo?text=https\%3A\%2F\%2Fhi-news.ru\%2Fscience\%2Fnas-zhdutdizajnerskie-mladency-i-novye-texnologii-sozdaniya-detej.html (проверено 25.07.2020). 
шение тревожности, эмоциональной подавленности, порождает цифровую зависимость. Не случайно так стремительно растет уровень детской преступности, общей агрессии, возникают депрессивные состояния и суицидальные настроения ${ }^{1}$.

Вполне естественно, что прорывные открытия и изобретения, сопутствующие современности, приводят к развитию знаний и появлению новой информации в различных сферах жизни. Все эти компоненты индустрии 4.0 требуют от человека ответственного подхода к моральным и этическим сторонам происходящих изменений. Но до сих пор нет прозрачных механизмов, которые будут регулировать соблюдение морально-этической стороны развития тотальных процессов цифровизации. Вполне естественно предположить, что если человек создал своим интеллектом «цифру», то и управлять этим созданным им мощным инструментом он должен по-человечески, не нарушая основной гуманистический принцип взаимодействия людей, нравственные основы их сосуществования на планете Земля.

В связи с этим встает вопрос об управлении: человек будет управлять «цифрой» или наоборот? Безусловно, стоит согласиться с мнением президента В.В. Путина, что в этой сфере не существует международного регулирования, но надо понимать, что главной проблемой цифровой экономики является вопрос, где она начинается и где заканчивается.

«Развитие цифровой экономики является стратегически важным вопросом для России в целом, определяющим ее конкурентоспособность на мировой арене. Необходимо признать тот факт, что в нашей стране на сегодняшний день, к сожалению, не сложились все необходимые условия для стихийного формирования зрелой цифровой экономики за приемлемый период времени. В первую очередь это продиктовано технологическими отставаниями и отсутствием критической массы экономических субъектов. Это значит, что ключевым драйвером относительно стимулирования и направления развития цифровой экономики должно стать государство» [Савина 2018: 580].

Все перечисленные тренды усложняются возрастающей скоростью изменений, что, в свою очередь, приводит к увеличению числа мощных рисков и вызовов. Одними из них становятся появление новых, ранее не виданных пандемических заболеваний, трансформация управления, преобладание технических и технологических возможностей использования цифровизации над социокультурными процессами. Скорость продвижения цифрового общества, экономические, технологические и социальные изменения приводят к созданию важнейших задач, таких как управление различными социальными объектами: государством, регионами, социальными институтами и организациями.

Цифровые технологии в современном мире - это не только инструмент, но и среда существования, которая открывает новые возможности: непрерывное образование, возможность проектирования индивидуальных образовательных маршрутов. Искусственный интеллект уже активно используется в различных профессиях, приближая конкуренцию или партнерство естественного и искусственного интеллекта.

Декан экономического факультета МГУ им. М.В. Ломоносова А.А. Аузан в одном из своих выступлений сказал, что, если мы хотим соответствовать вызовам цифровизации, то будущее такого образования - в сочетании математики (как производства алгоритмов) с широким гуманитарным образованием, даже,

\footnotetext{
1 Там же.
} 
точнее, образованием в области искусств, которое развивает эмоциональный интеллект студентов и все эти способности (soft skills) ${ }^{1}$.

Преимущество людей, по мнению декана, заключается в правополушарном мышлении и эмоциональном интеллекте. Пока искусственный интеллект этими инструментами еще не овладел (и неизвестно, овладеет ли вообще), это является нашим конкурентным преимуществом, которое подлежит развитию. С этим мы можем выходить на партнерство с искусственным интеллектом, а не на конкуренцию, которую мы рискуем проиграть 2 .

Данный тезис ученого как бы предупреждает о необходимости привлечения внимания системы образования к подготовке кадров для современной экономики, обеспечения ее конкурентоспособными, креативными, талантливыми выпускниками с использованием конвергентного подхода к учебному процессу. Привлечение гуманитарных технологий дает право говорить о создании новой конвергентной $N B I C S$-технологии, где $S$ - это социальные гуманитарные технологии [Баксанский 2014: 1061].

Если ориентироваться только на потребности цифрового общества, то это может вызвать доминирование технических наук, которое приведет к господству технократического мышления и, как следствие, к деградации гуманистической составляющей образования, архаизации общества. Обилие технических знаний не готовит людей к творческой мыслительной деятельности, а огромные неконтролируемые потоки информации трансформируют сущностные ценности человека, меняют их смысл и значение.

Креативная составляющая является важнейшей способностью личности и ключевым элементом человеческого капитала.

Определение понятия «креативная компетенция» (в трактовке американского исследователя Р. Эпштейна), выглядит следующим образом: это «готовность адаптивно использовать приобретенные знания, лично расширять концепцию знаний, прилагать усилия для самообразования и самосовершенствования». Автор выделяет структуру компетенции и ее элементы: методический (теоретическое понимание, риторика, способность к синтезу и анализу), процессуальный (принципы, способы и методы, которые включают в себя не только формирование замыслов и идей, но и весь процесс формирования решения вопроса); личностный (креативность, коммуникабельность); панорамный (различные условия и факторы формирования компетенции) [Epstein 2005].

Необходимость развития креативности отмечает и создатель группы Alibaba Джек Ма: «Мы должны учить детей быть инновационными, креативными и конструктивными, чтобы они могли выжить в эпоху искусственного интеллекта. Я хочу сделать для этого как можно больше» ${ }^{3}$.

В последнее время во многих странах мира интенсивно разрабатываются инновационные образовательные технологии в соответствии с актуальными потребностями социально-экономического развития. Все это имеет самое прямое отношение к задачам российской системы образования, в рамках которой с 2012 г. российские студенты регулярно выигрывают чемпионаты мира по программированию - важной отрасли мировой экономики 4 .

Реформирование системы высшего образования направлено на повыше-

1 Выступление А.А. Аузана в Совете Федерации. Доступ: http://council.gov.ru/events/ news/67300/ (проверено 25.07.2020).

2 Там же.

3 Джек Ма. Креативность стала важнее диплома. Доступ: https://www.spot.uz/ $\mathrm{ru} / 2019 / 10 / 21 / \mathrm{ma} /$ (проверено 25.07.2020).

4 Студенты МГУ выиграли чемпионат мира по программированию. Доступ: https://www. kommersant.ru /doc/3607808 (проверено 09.04.2020). 
ние качества «человеческого капитала» выпускников высшей школы, которые должны быть способны справиться с кризисными явлениями в области экономики и политики страны. При этом необходимо помнить, что система образования - это устойчивая составляющая социально-культурной жизни, в которой хранится и передается культурный код общества, а значит, нужно с осторожностью относиться к каким-либо непродуманным экспериментам.

Важным компонентом современной модели российского образования еще остаются фундаментальные знания и компетентностный подход, ориентация на практические навыки выпускников, способность применять знания, создавать и реализовывать собственные проекты.

Во многих странах разворачивается публичная дискуссия о том, с помощью каких механизмов должны формироваться компетенции и навыки, которые становятся базовыми в цифровом сообществе. В некоторых государствах проводятся полномасштабные реформы, ориентированные на создание полноценного образования для решения задач XXI в.: в Европе активно лидирует правительство Финляндии, в Азии - Сингапур.

Исследователи провели анализ состояния систем высшего образования в успешных странах «азиатских тигров» и выделили основные тренды: «усиление роли государства в мониторинге деятельности университетов, включая финансовую, образовательную и научную сферы, с целью поднятия престижа системы национального высшего образования в глобальных масштабах; проведение крупномасштабных реформ системы высшего образования, затрагивающих юридические и социально-экономические аспекты деятельности вузов, ориентированных на решение новых задач и вызовов, с которыми сталкивается человечество в 21 веке; восприятие образования как первоочередной задачи, от успешного решения которой во многом зависит качество общественных отношений, социальный состав нации, экономическое развитие государства и его общий престиж на мировой арене; глобализация и интернационализация контингента преподавателей и обучающихся как отражение новых процессов в мире и реализация принципов академической мобильности; усиление процессов отбора абитуриентов для создания более успешных студенческих сообществ; массовость высшего образования, сопровождаемая “образовательной лихорадкой” и целым рядом связанных с ней социальных, психологических и экономических проблем» [Исаева, Исаева 2019: 119-120].

Доклад «Российское образование в контексте международных индикаторов», подготовленный Федеральным институтом развития образования (ФИРО) РАНХиГС, впервые представил показатели отечественной системы образования, которые сопоставлены с показателями развитых стран, входящих в Организацию экономического сотрудничества и развития (ОЭСР). Уровень образования в стране прямо связывается с ее экономическим развитием ${ }^{1}$.

Было подтверждено, что Россия - одна их самых образованных стран в мире: $63 \%$ населения в возрасте от 25 до 64 лет имеют третичное образование (дипломы об окончании вузов и колледжей, где готовят специалистов среднего звена). По этому показателю из 46 стран - членов ОЭСР и партнеров Россия уступает только Ирландии и Канаде. В России также очень низкая доля людей с образованием ниже полного среднего - 5\%, 2-е место после Японии.

У каждой страны есть свои ответы на вызовы в сфере образования, и все страны по-разному на них реагируют. Одни, как, например, Финляндия, коренным образом ломают традиционные школьные программы и учебные планы и пере-

1 Бедные, но умные. Доступ: https://www.kommersant.ru/doc/4170764 (проверено 25.07.2020). 
ходят к курсам, объединяющим несколько предметов. Другие, как, например, Россия, идут по экстенсивному пути, наращивая объемы информации в учебных программах, ищут опору в прошлых достижениях национальной системы образования или пытаются перейти на европейскую систему образования.

«Прежде всего важно знать, к какому результату мы идем. Говорить об эффективности или неэффективности системы можно тогда, когда известно, чего конкретно хотим добиться. Проблема российского образования, возможно, заключается в том, что в основных документах четко не сформулировано, а лишь есть предположение, каким должен быть выпускник школы или каким специалистом будет, когда закончит вуз» ${ }^{1}$. Бесконечные трансформации системы высшего образования не обеспечивают в полной мере уверенный переход на цифровую экономику, характеризующуюся новыми трудовыми отношениями и развитием новых технологий. На современном рынке труда искусственный интеллект уже выполняет многие рутинные процессы. В настоящее время $41 \%$ опрошенных предпринимателей начали вкладывать средства в ускорение автоматизации, поскольку готовятся к работе в посткризисный, постпандемийный период. Следовательно, перед массой людей встанет проблема безработицы такие данные приводят эксперты британской аудиторско-консалтинговой компании Ernst\& Young 2 .

Современный мир непрерывно изменяется. Любой кризис всегда говорит о том, что нужно выходить на новый уровень осмысления человеческого существования. В различные сферы деятельности внедряются инновации, что, с одной стороны, ориентирует людей на постоянное развитие, совершенствование своих знаний, умений, компетенций, овладение новыми видами деятельности в смежных отраслях экономики. С другой стороны, рутинная работа все более передается машинам, а от человека требуется творчество, готовность сотрудничать с коллегами в поиске новых решений и, что особенно важно, умение критически оценить предлагаемую информацию как на предмет достоверности, так и с точки зрения ее логического встраивания в текущую задачу.

Таким образом, мы можем говорить о необходимости формирования у современного человека высокой информационной культуры как одной из важнейших задач социального управления, ведь тотальная цифровизация и внедрение на ее основе различных технологий представляют неизбежный естественный процесс, совпавший с глобальным экономическим кризисом. Данные изменения приведут к новому мироустройству, которое будет отличаться от традиционной системы ценностей, управленческих парадигм, социальных норм и экономических законов.

Принимая необходимость трансформационных изменений, следует отметить важность сохранения гуманистической составляющей образовательной системы, которая является стержневой основой нашего будущего. Не менее важно обеспечение информационной и экономической безопасности отдельного человека - защиты персональных данных и неприкосновенности частной жизни россиян в цифровом обществе, улучшения жизни всех социальных групп населения.

\section{Список литературы}

Баксанский О. Е.2014. Конвергенция знаний, технологий и общества: за пре-

\footnotetext{
1 Там же.

2 Работодатели по всему миру ускоряют внедрение роботов. Доступ: https://incrussia.ru/ news/roboti-protiv-coronavirusa/ (проверено 25.07.2020).
} 
делами конвергентных технологий. - Философия и культура. № 7(79). С. 10611068.

Бродовская Е. В.2019. Цифровые граждане, цифровое общество и цифровая гражданственность. - Власть. Т. 27. № 4. С. 65-69.

Исаева Т.Е., Исаева Е.С. 2019. Прыжск «азиатских тигров»: роль высшего образования в национальном сознании группы стран Восточной Азии: монография. Ростов н/Д: Изд-во РГУПС. 134 с.

Леньков Р.В., Боровлева Е.И. 2018. Современные процессы формирования и развития информационного общества знания. - Культура управления в России и Kuтае. М.: Изд-во ГУУ. С. 149-167.

Савина Т.Н. 2018. Цифровая экономика как новая парадигма развития: вызовы, возможности и перспективы. - Finance and Credit. Vol. 24. Is. 10. P. 579590.

Шаповалова И.С. 2015. Влияние интернет-коммуникаций на поведение и интеллектуальное развитие молодежи. - Социс. Социологические исследования. № 4. С. $148-151$.

Швецов А.Н. 2012. Информационное общество. Теория и практика становления в мире и в России. М.: Красанд. 280 с.

Epstein R. 2005. Generativity Theory and Creativity. - Theories of Creativity (ed. by M.A. Runco, R.S. Albert). Cresskill, NJ: Hampton Press.

RYBAKOVA Marina Vladimirovna, Dr.Sci. (Soc.), Chief Researcher of the Sociological Institute - branch of the Federal Center of Theoretical and Applied Sociology, Russian Academy of Sciences (bld. 5, 24/35 Krzhizhanovskogo St, Moscow, Russia, 117218); Professor of the Faculty of Public Administration, Lomonosov Moscow State University (bld. 4, 27 Lomonosovsky Ave, Moscow, Russia, 119991; Rybakovamv2005@yandex.ru)

ZERNOVA Lyudmila Pavlovna, Cand.Sci. (Philos.), Associate Professor of the Moscow Institute of Physics and Technology (MIPT) (9 Institutsky Lane, Dolgoprudny, Moscow Region, Russia, 141701; zlp55@yandex.ru)

\section{DIGITALISATION AND RUSSIAN EDUCATION: MANAGERIAL ASPECTS}

Abstract. The article discusses the problems associated with the digitalization of Russian society, as well as the main factors and challenges associated with the educational training of modern personnel to improve the competitiveness of the Russian economy in the global world. The authors show that the key factor of human capital productivity growth is the development of creativity and creative potential of modern school and university graduates.

Keywords: digitalization, social management, education, competence approach, creativity 